\title{
RANCANG BANGUN ALAT PANJAT UNTUK PENDERES NIRA KELAPA DI KABUPATEN BANYUMAS
}

\author{
${ }^{1}$ Achmad Zaki Yamani, ${ }^{2}$ Aswan Munang \\ ${ }^{1,2}$ Jurusan Teknik Industri, Fakultas Teknologi Industri dan Informatika, Institut Teknologi Telkom Purwokerto \\ Jalan D.I Pandjaitan No. 128 Purwokerto Selatan 53144 \\ e-mail: zaki@ittelkom-pwt.ac.id
}

\begin{abstract}
Coconut sugar is one of the leading commodities in Banyumas City, coconut sugar and it is derivative processing can make a high contribution to the development of the local economy of the community. This can be seen from the history of the production of coconut sugar whose trend is always increasing, in 2013 the production of coconut sugar was 206,026 tons / day, in 2014 it increased to 240 tons / day and in 2015 the production reached 250 tons / day. This study aims to find an area of improvement for the design of tree climbing aids that are in line with the expectations of the nira hikers in the Cilongok Banyumas City. In carrying out their work, the loudspeakers did not have much safety equipment, in a day, the loudspeakers had to climb 40 trees from morning to evening. The average height of each coconut tree that is climbed is around 20 until 30 meters. This study aims to design coconut climbing aids for the nira hardener with a quality function deployment (QFD) approach. In the process of retrieving data, the researcher identifies the desires of consumers, a questionnaire that has been determined and contains attributes in accordance with the quality plan that has been determined in the framework of the thought distributed to the subject. The way to find out the user anthropometry data is by measuring height, body dimensions, age, weight and length of work, so that we can obtain a reference for designing coconut tree climbing aids that are in accordance with the expectations of the palm fruit pusher.
\end{abstract}

Key words : Coconut Tree Climbing Tool; Coconut Sugar; Quality Function Deployment

\begin{abstract}
Abstrak
Gula kelapa merupakan salah satu komiditas unggulan Kabupaten Banyumas, Gula kelapa dan pengolahan turunanya mampu memberikan kontribusi yang tinggi terhadap pengembangan ekonomi lokal masyarakat. Hal ini bisa dilihat dari riwayat produksi gula kelapa trendnya selalu meningkat, tahun 2013 produksi gula kelapa 206,026 ton/hari, tahun 2014 meningkat menjadi 240 ton/hari dan pada tahun 2015 produksinya mencapai 250 ton/hari. Penelitian ini bertujuan menemukan area of improvement untuk perancangan alat bantu panjat pohon yang sesuai dengan harapan penderas nira di Kecamatan Cilongok Banyumas. Dalam menjalankan pekerjaanya, para penderas belum banyak memiliki peralatan keselamatan, dalam sehari, para penderas harus memanjat 40 pohon dari pagi hari hingga sore. Ketinggian rata-rata setiap pohon kelapa yang dipanjat sekitar 20 hingga 30 meter. Penelitian ini bertujuan untuk perancangan alat bantu panjat kelapa bagi penderas nira dengan pendekatan quality function deployment (QFD). Pada proses pengambilan data, peneliti mengidentifikasi keinginan konsumen, kuesioner yang sudah ditentukan dan berisi atribut-atribut sesuai dengan rencana mutu yang sudah ditentukan dalam kerangka pikir disebarkan kepada subyek. Cara untuk mengetahui data anthropometri user dilakukan dengan pengukuran tinggi badan, ukuran dimensi tubuh, umur, berat badan dan lama bekerja, sehingga dapat diperoleh acuan untuk mendesain alat bantu memanjat pohon kelapa yang sesuai dengan harapan penderas nira.
\end{abstract}

Kata kunci : Alat panjat Pohon Kelapa; Gula kelapa; Quality Function Deployment

\section{PENDAHULUAN}

Gula kelapa sebagai produk unggulan Kabupaten Banyumas, bagaimana hal tersebut memberikan kontribusi yang tinggi terhadap pengembangan ekonomi lokal. Kontribusi ini ditunjukkan dengan jumlah penderas nira kelapa yang mencapai 26.282 KK pada tahun 2015, serta memiliki sekitar 31.521 home industry nira kelapa pada tahun 2015 (Disperindag, 2016).Jumlah petani penderas terbanyak berada di Kecamatan Cilongok sebanyak 6.881 orang dengan jumlah produksi 45.234,35 ton/hari.

Potensi gula kelapa yang sedemikian besar ini ternyata belum dibarengi dengan pencegahan dan pengetahuan inklusif mengenai sisi keselamatan kerjanya (safety), karena rata-rata ketinggian pohon kelapa berkisar 20 hingga 30 meter, sehingga sangat dimungkinkan terjadi 
faal kerja yang bisa mengakibatkan kecacatan bahkan hingga kematian. Kecelakaan kerja penderas di Banyumas tercatat masih cukup tinggi, dari catatan Dinas Sosial Tenaga Kerja \& Transmigrasi (Dinsosnakertrans) Banyumas, setiap tahun terjadi hampir 70 lebih penderas meninggal dunia akibat jatuh dari pohon. Jumlah penderas di wilayah Banyumas sendiri termasuk cukup banyak mencapai 10 ribuan penderas yang tersebar di 27 kecamatan.

Kasus kecelakaan kerja yang di alami penderas/penyadap nira kelapa di Kab. Banyumas selama ini tergolong cukup tinggi.Berdasarkan data di Bagian Kesra Banyumas, sepanjang tahun 2016 jumlah kecelakaan kerja terjatuh dari pohon yang dialami penderas nira kelapa mencapai 119 kasus. Jumlah kasus kecelakaan tersebut, penderas yang meninggal mencapai 34 orang, sementara lainya mengalami luka-luka, bahkan beberapa orang di antaranya mengalami cacat permanen. "kata Kasubag Sosial, Kesehatan dan Keluarga Berencana Bagian Kesra, Tasro. (harian Republika.co.id edisi 19/01/2017).

Dalam menjalankan pekerjaanya,para penderas belum banyak memiliki peralatan keselamatan.Dalam sehari, para penderas harus memanjat 40 pohon dari pagi hari hingga sore. Ketinggian rata-rata setiap pohon kelapa yang dipanjat sekitar 20 hingga 30 meter. Sehingga dalam penelitian ini akan mengusulkan untuk perancangan alat bantu panjat kelapa bagi penderas nira dengan pendekatan Quality Function Deployment (QFD). Fokus utama dari Quality Function Deployment (QFD) adalah terletak pada kepentingan dan harapan pelanggan yang mengacu pada suara pelanggan, dan melibatkan pelanggan pada proses pengembangan produk sedini mungkin. Quality Function Deployment (QFD) menerjemahkan apa yang dibutuhkan pelanggan menjadi apa yang dihasilkan.

Penelitian tentang alat bantu panjat pohon sudah melalui beberapa penelitian sebelumnya. Salah satu diantaranya adalah penelitian tentang rancang bangun alat bantu panjat pohon kelapa untuk meningkatkan produktivitas petani kelapa (Agri et al, 2017), setelah diuji, secara fungsional alat bantu pemanjat pohon kelapa masih diperlukan pengembangan alat untuk faktor safety agar lebih optimal. Sehingga hal ini yang melatarbelakangi penelitian ini, utamanya untuk fokus dalam menemukan area of improvementuntuk perancangan alat bantu panjat pohon yang sesuai dengan harapan penderas nira di Kecamatan Cilongok Banyumas.

\section{METODE PENELITIAN}

Metode penelitian ini menggunakan pendekatan Quality Function Deployment (QFD) serta eksperimen yang akan dilakukan di Prodi Teknik Industri Institut Teknologi Telkom Purwokerto. Sistem yang dirancang pada penelitian ini melalui beberapa tahapan seperti ditunjukkan pada Gambar 1 dibawah ini. 


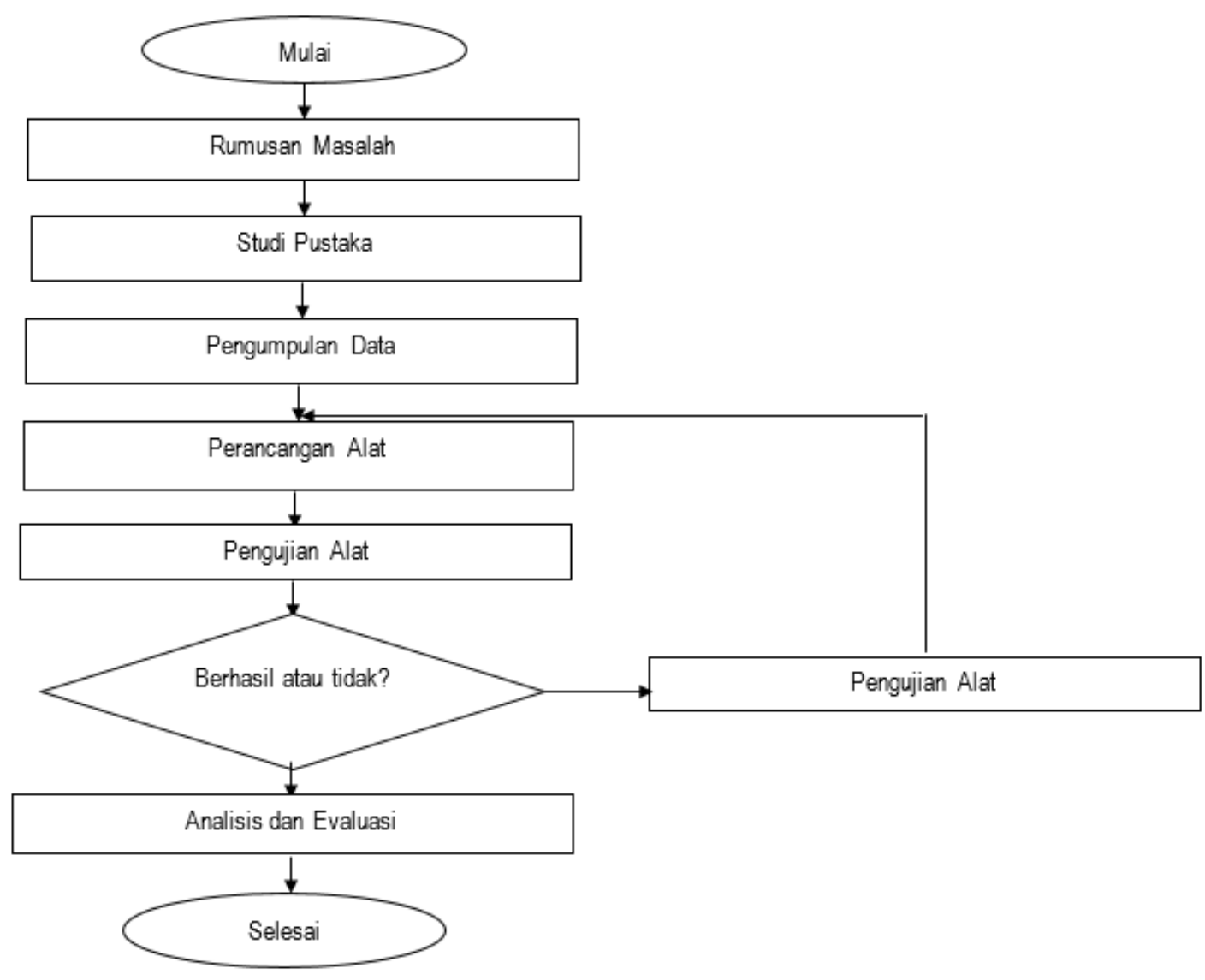

Gambar 1. Diagram alir penelitian

Dalam melakukan aktivitas penelitian diperlukan suatu metode yang sesuai dengan alur penelitian yang akan dilakukan, sedangkan langkah-langkah penelitian dalam mengimplementasikan Quality Function Deployment terdiri dari empat tahap, yaitu matrik perencanaan produk, matrik pengembangan desain, matrik perencanaan proses dan matrik perencanaan produksi.

\section{PENGUMPULAN DATA}

Untuk dapat mengidentifikasi keinginan konsumen, kuesioner yang sudah ditentukan dan berisi atribut-atribut sesuai dengan rencana mutu yang sudah ditentukan dalam kerangka pikir disebarkan kepada subyek. Untuk mengetahui anthropometry user dilakukan pengukuran tinggi badan, ukuran dimensi tubuh, umur, dan berat badan. Kuesioner akan diberikan kepada responden yang ada didalam bagian kelompok penderas nira kelapa di kecamatan Cilongok Kabupaten Banyumas.

Kuesioner akan berupa pilihan ganda dan esay, sehingga dapat mengakomodir pengalaman objek penelitian yang beragam. Kuesioner akan dibagikan kepada para penderas nira kelapa yang berjumlah 40 orang. Dari kuesioner tersebut diharapkan kuesioner bisa menjadi dasar penelitian perancangan alat bantu panjat kelapa untuk penderes nira. Pengukuran akan dilakukan sesuai dengan standart pengukuran seperti tertera di lampiran. Dari hasil pengukuran tersebut, akan dikelompokkan dalam table Microsoft Excell dan SPSS untuk kemudian dianalisis. 


\section{HASIL DAN PEMBAHASAN}

Identifikasi atribut didapat dari gabungan antara data-data dimensi kualitas dengan hasil wawancara. Penentuan spesifikasi dilakukan berdasarkan hasil pengisian kuesioner yang telah diisi oleh penderes nira kelapa. Pembuatan spesifikasi teknik terdiri dari atribut, matriks, spesifikasi teknik, satuan dan kriteria. Proses desain produk ini didasarkan hasil wawnacar, desain produk ditunjukkan pada gambar 2 .

\section{DESAIN PRODUK}
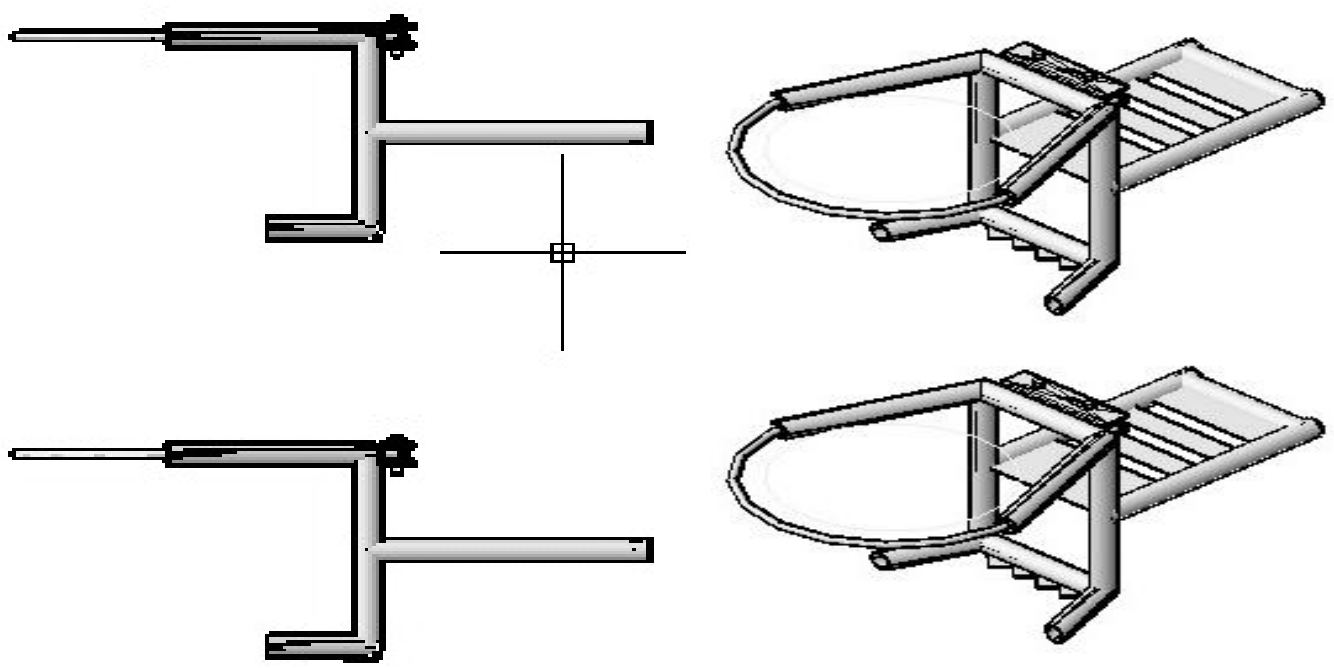

Gambar 2. Desain alat panjat pohon kelapa
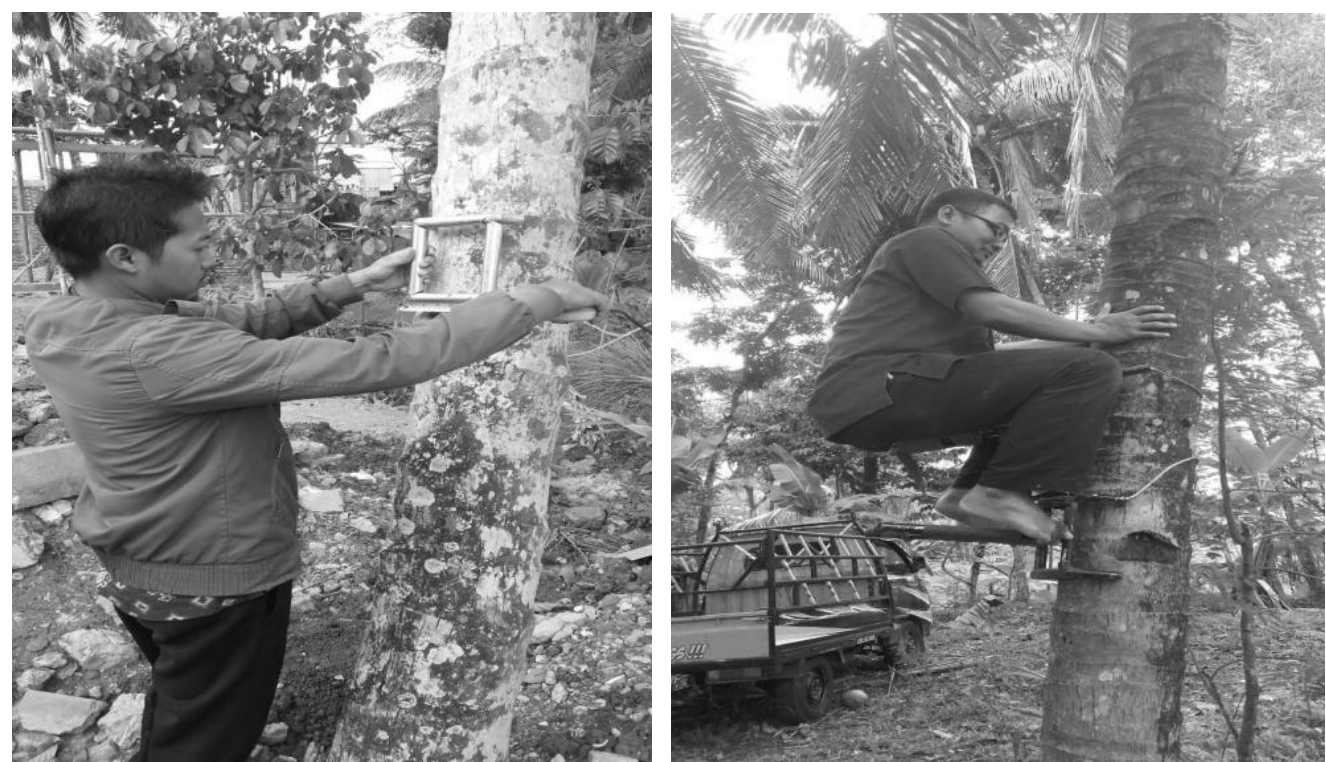

Gambar 3. Implementasi alat panjat pohon kelapa

Pada gambar 3 menunjukkan dokumentasi dari implementasi produk alat panjat pohon kelapa. Berdasarkan hasil pengamatan dan proses perakitan alat bantu panjat nira kelapa yang dilakukan, diketahui bahwa alat bantu panjat pohon kelapa yang dirancang memiliki dimensi 
panjang $54,5 \mathrm{~cm}$, lebar $37,3 \mathrm{~cm}$, tinggi $54,5 \mathrm{~cm}$ dengan berat total $5 \mathrm{~kg}$ untuk 1 set nya. Dengan perancangan alat panjat pohon kelapa dengan metode Quality Function Deployment (QFD) ini dapat membantu penderes nira kelapa dalam pekerjaanya serta memberikan rasa aman dari potensi cidera atau faal akibat kerja..

\section{SIMPULAN}

Dari hasil uji fungsional, alat bantu pemanjat pohon kelapa masih sangat memerlukan pengembangan alat untuk faktor safety agar lebih optimal, beberapa pengembangan yang bisa dilakukan adalah menyederhanakan proses set up alat agar lebih efisien dari sisi waktu pemakaian alat. Studi lanjut atau studi perbandingan dengan alat-alat panjat lain yang sudah pernah ada serta tinjauan sisi ekonomis perlu dilakukan untuk menyempurnakan penelitian ini menjadi lebih baik.

\section{UCAPAN TERIMA KASIH}

Penelitian ini didukung oleh LPPM IT Telkom Purwokerto yang telah membantu dan memberikan dukungan terkait dengan bantuan fasilitas penelitian, dana hibah, dan lainnya.

\section{DAFTAR PUSTAKA}

Aggraeni M., Desrianty A., Yuniar. (2013). Rancangan Meja Dapur Multifungsi Menggunakan Quality Function Deployment (QFD). Jurnal Online Institut Teknologi Nasional No. 2 Vol. 1. Bandung.

Cohen. (1995). Quality Function Deployment: How To Make QFD Work For You, AddisonWesley Publishing Co., Massachuetts.

Djumhariyanto, D. (2013). Rancang bangun flexy bike sebagai alat transportasi alternatif keluarga Indonesia. Jurnal Rotor Vol 6 No 2.

French, M. J. (1999). Conceptual Design for Engineers. London: Spinger-Verlag.

Handoko, S. (2013). Penciptaan alat panjat pohon kelapa. Jurnal Riset Daerah, XII (2).

Nugroho I. (2006). Perancangan alat pemanjat pohon kelapa penggerak manual. Bandung. Universitas Pasundan.

Nugroho, 1. (2006). Perancangan alat pemanjat pohon kelapa penggerak manual. Malang: University of Muhammadiyah Malang.

Somantri, H. (2015). Rancang Bangun Mesin Pemanjat Pohon Kelapa. Bandung: Universitas Pasundan. 
